\title{
Improving outcomes in chronic obstructive pulmonary disease: the role of the interprofessional approach
}

This article was published in the following Dove Press journal:

International Journal of COPD

26 June 2015

Number of times this article has been viewed

\author{
Bravein Amalakuhan ${ }^{1,2}$ \\ Sandra G Adams ${ }^{1,2}$ \\ 'Department of Medicine, Division \\ of Pulmonary Diseases/Critical Care \\ Medicine, The University of Texas \\ Health Science Center at San Antonio, \\ ${ }^{2}$ South Texas Veterans Health Care \\ System, Audie L. Murphy Division, San \\ Antonio, TX, USA
}

\begin{abstract}
Chronic obstructive pulmonary disease (COPD) is associated with significant morbidity, places substantial time and cost burden on the health care system, and is now the third leading cause of death in the US. Many interventions are available to appropriately manage patients with COPD; however, fully implementing these strategies to help improve outcomes may be difficult. Collaboration between an interprofessional team of health care professionals (which includes physicians, nurses, respiratory therapists, physical therapists, dietitians, pharmacists, and many others) and COPD patients and caregivers is necessary to optimally manage these patients and to truly impact outcomes in this devastating disease. Prescribing evidence-based non-pharmacological and pharmacological therapies is an important start, but a true team-based approach is critical to successfully implement comprehensive care in patients with COPD. The goal of this review is to employ a case-based approach to provide practical information regarding the roles of the interprofessional team in implementing strategies to optimally manage COPD patients.
\end{abstract}

Keywords: optimal care, shared decision-making, co-morbidities

\section{Case history}

Mrs $\mathrm{H}$ is a 55-year-old woman seen by a primary care clinician as a new patient to establish care after recently relocating to the area. She has a history of hypertension, hyperlipidemia, and tobacco use for the last 35 years. She currently smokes one and a half pack of cigarettes per day (reduced from two packs per day). Mrs $\mathrm{H}$ admits to dyspnea on exertion at $100 \mathrm{~m}$ and cough productive of white sputum, which have progressed over the last 2 years. She denies chest pain or pressure. She admits to symptoms of anxiety and depression, which have markedly worsened over the last year, but she denies suicidal ideation. Her husband reports that she frequently snores at night and appears to have intermittent pauses in her breathing before "gasping" for air. Mrs H reports an episode of "acute bronchitis and wheezing" about 6 months ago, which required 5 days of a systemic corticosteroid and an antibiotic. She denies childhood or family history of asthma, and allergic symptoms. Mrs H reports that she is compliant with her medications, which include a cardioselective beta-blocker and a statin. She is actively trying to quit smoking but is finding it difficult. Her body mass index (BMI) is $25 \mathrm{~kg} / \mathrm{m}^{2}$. Her alpha-1 antitrypsin level is normal, and her spirometry reveals a post-bronchodilator forced expiratory volume in 1 second $\left(\mathrm{FEV}_{1}\right)$ to forced vital capacity ratio of $60 \%$ and $\mathrm{FEV}_{1}$ of $55 \%$ of predicted. Mrs H's clinician classified her chronic obstructive pulmonary disease (COPD) as grade B based on the Global initiative for chronic Obstructive Lung Disease (GOLD) recommendations
Correspondence: Sandra G Adams South Texas Veterans Health Care System, Audie L. Murphy Memorial Veterans Hospital, Pulmonary Diseases Section (I I IE), 7400 Merton Minter Boulevard, San Antonio, TX 78229, USA $\mathrm{Tel}+\mathrm{I} 2106175256$

Fax +I 2109493006

Email adamssg@uthscsa.edu 
and prescribed a short-acting beta agonist inhaler (as needed) and a long-acting muscarinic antagonist (LAMA) inhaler (scheduled). How can an interprofessional/multidisciplinary approach be applied to provide Mrs $\mathrm{H}$ with optimal care at this point?

\section{Partnership between health care professionals and COPD patients and caregivers}

Most health care professionals see their COPD patients every few months; however, patients have to deal with their disease every minute of every day. Therefore, it is important for all health care professionals to partner with COPD patients and caregivers in order to achieve the best outcomes. This partnership should include working together to optimize non-pharmacological interventions such as 1) obtaining smoking cessation counseling for those who continue to smoke and reinforcing sustained abstinence for those who formerly smoked, 2) administering appropriate vaccinations, 3) participating in a pulmonary rehabilitation (PR) program and then continuing with increased physical activity throughout their lives, 4) maintaining optimal body weight to avoid pulmonary cachexia syndrome, and 5) appropriately managing the multiple morbidities that commonly occur in patients with COPD. In addition, health care professionals need to continue to work with COPD patients and their caregivers to ensure appropriate delivery of the prescribed pharmacotherapy.

\section{Smoking cessation counseling}

International organizations, societies, and initiatives recommend tobacco cessation for all patients with COPD. The US Preventative Services Task Force, the World Health Organization, National Institute for Health and Clinical Excellence, the Canadian Thoracic Society (CTS), and GOLD emphasize that smoking abstinence is the most effective intervention that reduces the progression, morbidity, and mortality associated with COPD. ${ }^{1-8}$ However, achieving sustained tobacco abstinence is one of the most difficult behavioral changes for patients to implement. ${ }^{9,10}$ Interprofessional approaches to smoking cessation begin with the initial encounter with the health care clinician who makes the diagnosis of COPD, and continue throughout the patient's care by the entire health care team. Interprofessional interventions including emotional support, counseling, and educational classes combined with pharmacotherapy improve rates of smoking cessation. ${ }^{11}$ Rates of sustained tobacco abstinence are poor, and range from only $5 \%$ (just by telling patients that smoking cessation is the best thing for their health) to nearly $35 \% .{ }^{12}$ Considering this, health care professionals and COPD caregivers should emphasize the importance of quitting and consistently provide positive reinforcement for patients' efforts during ongoing attempts as well as once smoking cessation is achieved to ensure continued abstinence. ${ }^{11,13-17}$ Like all patients with COPD who smoke, Mrs H should receive a consistent, caring, and nonjudgmental message from her entire health care team that smoking cessation/abstinence is critical to improve her COPD outcomes and improve her health. Therefore, she should receive a combination of smoking cessation counseling and pharmacotherapy to help her quit.

\section{Vaccinations}

Considering that $50 \%-70 \%$ of COPD exacerbations are caused by infections, the GOLD committee through their summary statements and the CTS/CHEST (American College of Chest Physicians) guidelines for the prevention of acute exacerbation of COPD (AECOPD) recommend influenza and pneumococcal vaccines for all patients with COPD.,18 Despite good intentions, clinicians often have difficulty remembering to offer vaccinations to all patients with COPD; therefore, an interprofessional approach is crucial to improve rates of appropriate vaccinations in this population. ${ }^{19}$ Finally, influenza and pneumococcal vaccines have been shown to decrease COPD exacerbations and improve outcomes, ${ }^{19}$ and thus, Mrs H should stay up-to-date on all appropriate vaccinations.

\section{Pulmonary rehabilitation}

PR programs have been shown to have a multifactorial benefit for patients with COPD, which is not just limited to improved exercise capacity. ${ }^{2,20}$ Its benefits occur whether performed as an inpatient, outpatient, or even at home, with the ideal location based on patient preference, cost, and availability. ${ }^{21,22}$ In terms of objective outcomes, PR decreases hospitalization rates, hospital length of stay, and mortality, and enhances the effect of long-acting bronchodilators. ${ }^{23,24}$ Furthermore, PR also improves perceived breathlessness, health-related quality of life, relative social isolation, as well as anxiety and depression associated with COPD. ${ }^{24-26}$ These factors impact the overall sense of well-being of patients with COPD, which for most patients is the most important outcome. Unfortunately, these beneficial effects wane over time if patients do not continue with the strategies learned in the PR program. Therefore, patients often return to their baseline status within approximately 2 years after completing a PR program. ${ }^{27}$ For this reason, patients should be encouraged to stay active even after completing a 6- to 10 -week PR program to help sustain 
the extensive benefits mentioned above. ${ }^{2,28,29}$ Simply walking $10-45$ minutes/day will likely be of benefit. ${ }^{28,30}$ Even patients with lower extremity disabilities have options in these diverse PR programs, such as upper extremity exercises that also have benefits. ${ }^{2,31}$ Considering these multiple benefits, Mrs $\mathrm{H}$ should be encouraged to participate in a PR program, and then to continue an active lifestyle even after completing this program. Further emphasizing the importance of an interprofessional approach, primary care clinicians and pulmonologists should recognize key comorbidities and physical limitations, discuss them with patients and caregivers, and then work closely with trained PR personnel to implement a program that is safe and effective.

\section{Nutrition}

Pulmonary cachexia, which is defined as significant weight loss from severe forms of pulmonary disease, affects more than one-third of patients with moderate-to-very severe COPD and has been shown to be an independent risk factor for mortality. ${ }^{32}$ Furthermore, there are consistent data on the association of low (ie, $<20 \mathrm{~kg} / \mathrm{m}^{2}$ ) BMI itself and increased mortality. ${ }^{33}$ Nutritional supplementation alone has not been shown to improve outcomes, but when coupled with dietary counseling, patients report improved quality of life, dyspnea, and functional status. ${ }^{34}$ Thus, Mrs H's weight should be monitored closely, and she should be advised to maintain her current body weight and not attempt to lose weight. The "American Lung Association" and the "Academy of Nutrition and Dietetics" recommend referral of patients with COPD to a certified dietitian with experience in COPD, in order to meet these weight goals as patients' lung function deteriorates over time. An interprofessional approach begins with primary care clinicians who recognize the development of pulmonary cachexia at an early stage, seek collaboration with a trained dietician, and then together, counsel patients and their caregivers on dietary habits.

\section{Management of comorbidities}

A unique characteristic of patients with COPD contributing to management challenges for health care professionals is the number and severity of concomitant chronic medical conditions. Patients with COPD have twice the number of chronic illnesses compared to their non-COPD counterparts (four vs two). ${ }^{35}$ Furthermore, greater than $50 \%$ of deaths in patients with COPD are in fact related to these comorbidities. ${ }^{36}$ Thus, focusing only on their airway obstruction will produce suboptimal outcomes. ${ }^{37}$

\section{Heart disease}

Ischemic heart disease (IHD) and COPD have common risk factors, and thus, it is not surprising that the most common comorbidity in patients with COPD is indeed IHD. ${ }^{2}$ Furthermore, COPD has been shown to be an independent risk factor for the development of IHD. ${ }^{35}$ Patients with both COPD and IHD have higher hospitalization rates, greater number of exacerbations, and higher mortality rates than those with COPD alone. ${ }^{38}$ IHD is one of the leading causes of death in patients with COPD, and thus, effective treatment directed toward this coexisting condition is the key. ${ }^{2,39}$ The GOLD recommendations emphasize that the treatment of IHD and heart failure in patients with COPD should follow the usual IHD/heart failure guidelines. Of particular importance is the use of cardioselective beta-blockers in patients with coexisting disease. Short-term studies have consistently shown that these medications are safe in patients with COPD and do not lead to significant bronchoconstriction. ${ }^{2}$ The long-term outcomes are uncertain, but the significant mortality benefit with selective beta-blockers in COPD patients with heart disease is considerably larger than the potential risks in these patients, regardless of the GOLD grade. Thus, Mrs H should be encouraged to maintain compliance with her cardioselective beta-blocker and other cardiac medications. If her symptoms progress, it would be prudent to obtain a transthoracic echocardiogram to evaluate her heart function, with prompt referral to a cardiologist if there are any treatable structural abnormalities. An interprofessional approach involving early differentiation of cardiac from pulmonary signs/symptoms by a primary care clinician and then collaboration with a cardiologist for diagnostic work-up and therapy would optimize outcomes. Following this, a comprehensive discussion with the patient and caregivers regarding lifestyle modifications, with regular exercise (as described in the "Pulmonary rehabilitation" section) as well as healthy eating habits, would be the key. Collaboration with a nutritionist would also be valuable to help with education and to provide healthy food options. The primary care clinician's role in continued positive reinforcement of these lifestyle changes is paramount.

\section{Osteoporosis}

COPD and osteoporosis are also strongly linked because of not only common risk factors such as age, smoking, and inactivity but also disease-specific factors related to COPD such as low BMI and prior corticosteroid use. ${ }^{40}$ Osteoporosis has also been correlated with low $\mathrm{FEV}_{1} \cdot{ }^{17}$ For this reason, it is understandable that greater than one-third of patients with 
COPD also have osteoporosis. ${ }^{41}$ Osteoporosis and resulting fragility fractures result in impaired mobility, which increases morbidity. ${ }^{40}$ Furthermore, vertebral compression fractures and rib cage fractures have also been shown to reduce pulmonary function, as well as increase rates of COPD exacerbations and mortality. ${ }^{40}$ The American Association of Clinical Endocrinologists and the US Preventative Services Task Force recommend a daily weight-bearing exercise routine of 30 minutes per day and smoking cessation to avoid bone loss and prevent osteoporotic fractures. Mrs $\mathrm{H}$ has multiple risk factors for osteoporosis with related fractures, and thus, an interprofessional approach involving early screening by her primary care clinician and then collaboration with nutritionists and physical therapists to assist with dietary changes and physical mobility exercises/PR should be utilized. An endocrinologist may also be consulted if osteoporosis becomes severe and advanced pharmacotherapy is needed.

\section{Anxiety and depression}

Anxiety and depression are comorbidities that have a multifactorial impact on patients with COPD and are often underappreciated, with Mrs $\mathrm{H}$ being a prime example of this. In fact, anxiety and/or depression are found in up to $65 \%$ of patients with COPD. ${ }^{42}$ Furthermore, the incidence and severity of these conditions increase with acute exacerbations and as $\mathrm{FEV}_{1}$ declines. ${ }^{42,43}$ It is not surprising that these conditions impact compliance with COPD medications, and thus have a significant indirect impact on outcomes. Cognitive behavioral therapy (CBT) and physical exercise/PR have been shown to have a positive impact on these conditions, and should be strongly recommended as treatment options for patients with COPD, including Mrs H. ${ }^{2,44}$ Studies have shown that 3 months of treatment with selective serotonin reuptake inhibitors (SSRIs) can decrease symptoms of depression while improving walking distance and degree of breathlessness. ${ }^{45}$ Thus, a prescription for an SSRI should be considered for Mrs H after attempting CBT and PR. Benzodiazepines have also been shown to be helpful for anxiety but should be used with caution and in low doses because of the increased risk of hypercapnia and COPD exacerbations in patients with severe COPD. ${ }^{46}$ In addition, other agents, such as buspirone, may be useful in select patients with COPD. ${ }^{47}$ An interprofessional approach with early recognition of these symptoms and referral by primary care clinicians to therapists skilled in CBT and PR is the key to the management of these conditions when they coexist with COPD. Furthermore, if these therapies do not have an impact on a patient's anxiety and depression, primary care clinicians should collaborate with psychiatrists to help titrate and adjust pharmacotherapy. Considering the stigma attached to anxiety and depression, referral should only be made after a nonjudgmental and collective discussion with the patient and his/her caregivers about the benefits of pursuing such treatment. The negative and multifactorial influence that anxiety and depression have on COPD clearly requires a multifaceted team of professionals to mitigate the impact.

\section{Obstructive sleep apnea (OSA)}

Up to one in five patients with COPD also suffer from OSA, and it is likely that Mrs $\mathrm{H}$ does as well. ${ }^{48}$ Coexisting OSA may result in more pronounced daytime hypercapnia, nocturnal hypoxemia, and the long-term development of pulmonary hypertension. ${ }^{48}$ Understandably, it has been shown that coexisting OSA is associated with increased risk of COPD exacerbations and mortality. ${ }^{49}$ Optimization of COPD medications, supplemental oxygen, and continuous positive airway pressure (CPAP) are treatments that have been shown to not only improve the symptoms of OSA but also improve survival. ${ }^{50}$ Considering Mrs H's nighttime symptoms, her primary care clinician should first screen her for negative sleep hygiene, and then collaborate with a physician who specializes in sleep medicine so that she may obtain a sleep study. This collaborative interprofessional approach will not only allow for effective diagnoses of her specific sleep pathology but also aid in effective treatment and educational counseling for patients and their caregivers. This team approach will allow for continued compliance once treatment is initiated.

\section{Inhaler technique, education, and self-management}

Starting from the first prescription and every follow-up visit thereafter, health care professionals should ensure that COPD patients and their caregivers appropriately exhibit the proper inhaler technique for each prescribed device. Step-by-step inhaler/nebulizer instructions in the form of videos are available online at no cost on the WipeCOPD ${ }^{\mathrm{TM}}$ YouTube $^{\circledR}$ channel. Previous studies have illustrated that more than half of patients with COPD use poor and ineffective inhalation techniques when utilizing their inhalers. ${ }^{51}$ Furthermore, studies have shown that patients who utilize proper inhaler techniques have decreased rates of COPD exacerbations and health care costs. ${ }^{52}$ For this reason, it is important to teach Mrs $\mathrm{H}$ and her caregiver/family about the correct way to use her prescribed inhalers. Proper technique for taking metered dose inhalers (MDIs) requires effective 
hand-mouth coordination, including inhaling in a slow, deep, and controlled manner and an appropriate breath hold after inhalation. ${ }^{53}$ Coordinating actuation and inhalation is the most commonly reported difficulty with MDIs, and can be improved by using a spacer device. ${ }^{54}$ In contrast, drypowder inhalers require a deep and forceful inhalation to effectively deliver the medication, but patients should still follow inhalation with an appropriate breath hold. ${ }^{17}$ MDIs, when used appropriately with a spacer device, dry-powdered inhalers, and nebulizers, are equally effective at controlling symptoms but only when used correctly. ${ }^{55}$ Thus, choice of medication delivery method should be based on patient comfort, preference, and level of coordination.

On her first visit, it is important not only to teach $\mathrm{Mrs} \mathrm{H}$ effective inhaler technique but also to emphasize the importance of medication compliance. Medication compliance in patients with COPD has been shown to reduce hospitalization rates ${ }^{56}$ and decrease mortality. ${ }^{57}$ Furthermore, belief that their treatment will be effective also improves medication adherence, ${ }^{58}$ thus emphasizing the importance of patient education on the value of these medications.

In addition to adherence to appropriate inhaled medications, educating Mrs H on the "warning signs" of an AECOPD and when to seek medical attention is important. ${ }^{59,60}$ The CTS/ CHEST guidelines on AECOPD recommend education with a written action plan and case management for the prevention of emergency department visits and hospitalization for severe AECOPD, particularly for those with a history of prior acute exacerbations. ${ }^{18}$ Several studies demonstrated reduced rates of hospitalizations and mortality when such an action plan is implemented but only when associated with an effective change in patient behavior where patients actually self-administer treatment earlier. ${ }^{59,61}$ The CTS/CHEST recommendation reflects the fact that only one study by Fan et al reported increased mortality in the intervention group, while the majority of studies supported the value of a written action plan and case management. ${ }^{62}$ In the study with increased mortality, patients were educated and provided with a COPD action plan, but the patients in the intervention/ action plan group continued to delay treatment for the same amount of time as the usual care group, which was on average 7 days. ${ }^{62}$ Although the specific reason for increased mortality in this one study is not known, patients with underlying severe disease and clinical instability need close attention and careful follow-up. This point emphasizes that specially trained interprofessional clinicians and other health care professionals are required to supervise this intervention, and patient selection must be individualized.

\section{Potential barriers to deployment of the above "ideal COPD treatment strategies"}

The above strategies have been shown to improve outcomes in patients with COPD, and every attempt should be made to implement them. That being said, not all patients have access to these resources. Patients working full time may not be able to visit their physicians and the other members of their interprofessional team every 3 months. Furthermore, health insurance may not pay for PR or dieticians. For that matter, public health services in certain areas of the country may not even have pulmonologists or sleep physicians practicing nearby, or offer services such as PR. The burden of these limitations often falls on the shoulders of the primary care clinician, the unsung hero of our health care system. Primary care clinicians who have many working patients in their practice might consider having 1 day per month where they have late afternoon/ evening clinic hours or a half-day weekend clinic to provide access to working COPD patients who have difficulty taking time off from work. In rural areas, where access to subspecialists is difficult to obtain, telemedicine may be a helpful adjunct to implement important treatment strategies. If patients are not able to physically go to PR (due to time or insurance limitations), primary care clinicians can utilize online and other resources and help patients design an individualized exercise regimen that the patients can perform at home. As described earlier, simply walking 10-45 minutes/day will likely be of benefit. ${ }^{28,30}$ Although not all these medical compromises are optimal strategies, they do offer some benefit. Considering studies have shown that patient belief that a treatment will be effective improves compliance and adherence to physician recommendations,${ }^{58}$ patient education and consistent reinforcement are the key to maintaining positive outcomes in this underserved population.

\section{Case of Mrs H (continued): 6 years later (6 I years old)}

Despite optimal management with an interprofessional approach, Mrs H's lung function and clinical status continued to deteriorate. She successfully stopped smoking (her last cigarette was on her 59th birthday). She has had a couple of episodes of AECOPD treated as an outpatient over the last 2 years. In addition, she was hospitalized last year for a severe AECOPD despite being compliant with her exercise program, vaccinations, and inhaled medications with a long-acting beta agonist and inhaled corticosteroid combination agent and an inhaled LAMA. Her most recent $\mathrm{FEV}_{1}$ (measured $\sim 12$ weeks after her hospitalization) is 
$32 \%$ of predicted, and her resting pulse oximetry on room air is $86 \%$. She wears $2 \mathrm{~L}$ of supplemental oxygen by nasal cannula continuously throughout the day and night but now reports dyspnea with activities of daily living such as dressing and bathing. She was diagnosed with OSA after a sleep study, and currently wears a CPAP at night. Her primary care clinician refers her to a center for evaluation for lung transplantation.

\section{Lung transplantation}

Lung transplantation is an option for a selected group of patients with very severe COPD despite optimal medical therapy who are severely symptomatic. ${ }^{2,63}$ COPD is one of the leading indications for lung transplantation. ${ }^{64}$ Lung transplantation has been shown to improve quality of life, lung function, and functional capacity. ${ }^{63}$ The impact of lung transplant on survival on the other hand is unclear, but some studies show that when appropriate selection criteria are applied, a significant survival benefit can be achieved. ${ }^{64}$ Current literature show that 1-year survival rates are $82.5 \%$, with survival rates dropping to $66.3 \%$ at 3 years, $53 \%$ at 5 years, and $26.4 \%$ at 10 years. ${ }^{65}$ Furthermore, patients with COPD have been shown to have an improved survival when undergoing a bilateral lung transplant compared to single transplants. ${ }^{66}$ Although mortality rates may be similar for those patients with COPD grades 3 and 4 who do not undergo lung transplantation, the survival period consists of improved quality of life and functional capacity, which for some patients makes the difficult postoperative recovery period worth having the procedure. ${ }^{66} \mathrm{Mrs} \mathrm{H}$ was rightfully referred to a center that specialized in lung transplantation for comprehensive counseling so that she could make an informed decision.

\section{Summary/wrap up}

For patients with COPD, the benefits of an interprofessional collaboration among various health care professionals themselves, as well as in conjunction with their patients and caregivers, cannot be underscored. It is important not only for timely implementation of therapy but also to ensure continued compliance, which is the foundation for success of any treatment plan. Central to this interprofessional team is the primary care clinician who is the first line of contact with the health care system for patients with COPD. It is essential for primary care clinicians to work closely with pulmonologists to consistently emphasize the importance of smoking cessation and to ensure that abstinence is maintained once achieved. Furthermore, clinicians should work with nurses, clinic support staff, and information technology to ensure that vaccinations are up-to-date at each clinic visit to avoid lapses in care. These health care professionals should also collaborate with therapists to ensure the development of a patient-specific PR program. After completing a formalized PR program, all patients should work together with their health care professionals and their caregivers to design a feasible daily exercise routine that will maximize long-term compliance. Primary care clinicians and pulmonologists should also ensure collaboration with a trained nutritionist to avoid pulmonary cachexia. Nutritionists will help design healthy meal plans that are both cost-effective and easy to prepare for patients and their caregivers. Nurses, respiratory therapists, COPD educators, and the clinic support staff have a crucial role in the optimal management of these complicated COPD patients. In addition, referrals to subspecialists should be considered as clinically indicated, including cardiologists, endocrinologists, psychiatrists, and trained sleep physicians, with a similar team-based approach involving open communication with each other, the primary care clinician, the patients, and their caregivers. Therefore, implementing an interprofessional team approach involving health care professionals working closely with COPD patients and caregivers is critical to achieving optimal outcomes in these patients.

\section{Key learning points}

- Fostering a collaborative relationship between health care professionals, COPD patients, and their caregivers is required to impact outcomes. This three-point triangular relationship requires mutual feedback and positive reinforcement in a nonjudgmental environment.

- All members of the interprofessional team should emphasize the importance of smoking cessation on every visit. Sustained smoking abstinence should be met with consistent positive reinforcement. Relapses are common and expected, and should be met with supportive and nonjudgmental rhetoric.

- All members of the interprofessional team should ensure that vaccinations are up-to-date.

- For those who meet criteria for PR, prompt referral should be made. For those who do not have access to PR, the patient's health care professional should help the patient design a home exercise plan. All PR strategies should focus on long-term compliance, extending beyond the classic 6- to 10-week program initially prescribed.

- Nutritional supplementation, when coupled with dietary counseling, may help improve clinical outcomes. 
- Effective management of comorbidities is as important as management of COPD itself in improving overall outcomes. Important comorbidities include heart disease, osteoporosis, depression, anxiety, and OSA.

- Effective inhaler technique should be emphasized and reinforced at every visit.

- Potential barriers to implementation of specific COPD management strategies should be investigated, and solutions sought before prescribing them. This will avoid unnecessary delays in treatment.

\section{Disclosure}

Sandra Adams has funded research by National Institute of Health, Veterans Affairs Cooperative Studies Program, CHEST Foundation, University of Texas System Patient Safety Grant, AstraZeneca Pharmaceuticals LP, Boehringer Ingelheim Pharmaceuticals, Inc, GlaxoSmithKline, and Novartis Pharmaceuticals AG, and is the President of a not-for-profit organization entitled WipeDiseases Foundation. Bravein Amalakuhan reports no conflict of interest in this work.

\section{References}

1. Celli BR, MacNee W. Standards for the diagnosis and treatment of patients with COPD: a summary of the ATS/ERS position paper. Eur Respir J. 2004;23(6):932-946.

2. From the Global Strategy for the Diagnosis MaPoC. Global Initiative for Chronic Obstructive Lung Disease (GOLD). 2015. Available from: http://www.goldcopd.org/

3. Anthonisen NR, Connett JE, Enright PL, Manfreda J. Hospitalizations and mortality in the Lung Health Study. Am J Respir Crit Care Med. 2002;166(3):333-339.

4. Fletcher C, Peto R. The natural history of chronic airflow obstruction. Br Med J. 1977;1(6077):1645-1648.

5. Hersh CP, DeMeo DL, Al-Ansari E, et al. Predictors of survival in severe, early onset COPD. Chest. 2004;126(5):1443-1451.

6. Scanlon PD, Connett JE, Waller LA, et al; Lung Health Study Research Group. Smoking cessation and lung function in mild-to-moderate chronic obstructive pulmonary disease. The Lung Health Study. Am J Respir Crit Care Med. 2000;161(2 pt 1):381-390.

7. Kanner RE, Connett JE, Williams DE, Buist AS. Effects of randomized assignment to a smoking cessation intervention and changes in smoking habits on respiratory symptoms in smokers with early chronic obstructive pulmonary disease: the Lung Health Study. Am JMed. 1999; 106(4):410-416.

8. Makris D, Moschandreas J, Damianaki A, et al. Exacerbations and lung function decline in COPD: new insights in current and ex-smokers. Respir Med. 2007;101(6):1305-1312.

9. Tashkin D, Kanner R, Bailey W, et al. Smoking cessation in patients with chronic obstructive pulmonary disease: a double-blind, placebocontrolled, randomised trial. Lancet. 2001;357(9268):1571-1575.

10. Jiménez-Ruiz CA, Masa F, Miravitlles M, et al. Smoking characteristics: differences in attitudes and dependence between healthy smokers and smokers with COPD. Chest. 2001;119(5):1365-1370.

11. van der Meer RM, Wagena EJ, Ostelo RW, Jacobs JE, van Schayck CP. Smoking cessation for chronic obstructive pulmonary disease. Cochrane Database Syst Rev. 2003;2:Cd002999.

12. Ebbert JO, Hughes JR, West RJ, et al. Effect of varenicline on smoking cessation through smoking reduction: a randomized clinical trial. JAMA. 2015;313(7):687-694.
13. Stead LF, Lancaster T. Group behaviour therapy programmes for smoking cessation. Cochrane Database Syst Rev. 2005;2:Cd001007.

14. Lancaster T, Stead LF. Individual behavioural counselling for smoking cessation. Cochrane Database Syst Rev. 2005;2:Cd001292.

15. Strassmann R, Bausch B, Spaar A, Kleijnen J, Braendli O, Puhan MA. Smoking cessation interventions in COPD: a network meta-analysis of randomised trials. Eur Respir J. 2009;34(3):634-640.

16. Tønnesen P, Carrozzi L, Fagerström KO, et al. Smoking cessation in patients with respiratory diseases: a high priority, integral component of therapy. Eur Respir J. 2007;29(2):390-417.

17. Sonetti DA, Hospenthal AC, Adams SG. Integrated management strategies for chronic obstructive pulmonary disease. J Multidiscip Healthc. 2010;3:181-188.

18. Criner GJ, Bourbeau J, Diekemper RL, et al. Executive summary: prevention of acute exacerbation of chronic obstructive pulmonary disease: American College of Chest Physicians and Canadian Thoracic Society guideline. Chest. 2015;147(4):883-893.

19. Cimen P, Unlu M, Kirakli C, et al. Should patients with COPD be vaccinated? Respir Care. 2015;60(2):239-243.

20. Spruit MA, Singh SJ, Garvey C, et al; ATS/ERS Task Force on Pulmonary Rehabilitation. An official American Thoracic Society/European Respiratory Society statement: key concepts and advances in pulmonary rehabilitation. Am J Respir Crit Care Med. 2013;188(8):e13-e64.

21. Lacasse Y, Brosseau L, Milne S, et al. Pulmonary rehabilitation for chronic obstructive pulmonary disease. Cochrane Database Syst Rev. 2002; 3:Cd003793.

22. Maltais F, Bourbeau J, Shapiro S, et al; Chronic Obstructive Pulmonary Disease Axis of Respiratory Health Network, Fonds de recherche en santé du Québec. Effects of home-based pulmonary rehabilitation in patients with chronic obstructive pulmonary disease: a randomized trial. Ann Intern Med. 2008;149(12):869-878.

23. Foglio K, Bianchi L, Ambrosino N. Is it really useful to repeat outpatient pulmonary rehabilitation programs in patients with chronic airway obstruction? A 2-year controlled study. Chest. 2001;119(6): 1696-1704.

24. Griffiths TL, Burr ML, Campbell IA, et al. Results at 1 year of outpatient multidisciplinary pulmonary rehabilitation: a randomised controlled trial. Lancet. 2000;355(9201):362-368.

25. Lacasse Y, Goldstein R, Lasserson TJ, Martin S. Pulmonary rehabilitation for chronic obstructive pulmonary disease. Cochrane Database Syst Rev. 2006;4:Cd003793.

26. Emery CF, Schein RL, Hauck ER, MacIntyre NR. Psychological and cognitive outcomes of a randomized trial of exercise among patients with chronic obstructive pulmonary disease. Health Psychol. 1998; 17(3):232-240.

27. Group CPRC. Effects of pulmonary rehabilitation on dyspnea, quality of life, and healthcare costs in California. J Cardiopulm Rehabil. 2004; 24(1):52-62.

28. Esteban C, Quintana JM, Aburto M, et al. Impact of changes in physical activity on health-related quality of life among patients with COPD. Eur Respir J. 2010;36(2):292-300.

29. Garcia-Aymerich J, Lange P, Benet M, Schnohr P, Anto JM. Regular physical activity reduces hospital admission and mortality in chronic obstructive pulmonary disease: a population based cohort study. Thorax. 2006;61(9):772-778.

30. Mahler DA. Pulmonary rehabilitation. Chest. 1998;113(4 suppl): $263 \mathrm{~s}-268 \mathrm{~s}$.

31. Belman MJ, Botnick WC, Nathan SD, Chon KH. Ventilatory load characteristics during ventilatory muscle training. Am J Respir Crit Care Med. 1994;149(4 pt 1):925-929.

32. Chailleux E, Laaban JP, Veale D. Prognostic value of nutritional depletion in patients with COPD treated by long-term oxygen therapy: data from the ANTADIR observatory. Chest. 2003;123(5):1460-1466.

33. Montes de Oca M, Tálamo C, Perez-Padilla R, et al; PLATINO Team. Chronic obstructive pulmonary disease and body mass index in five Latin America cities: the PLATINO study. Respir Med. 2008; 102(5):642-650. 
34. Ferreira IM, Brooks D, Lacasse Y, Goldstein RS, White J. Nutritional supplementation for stable chronic obstructive pulmonary disease. Cochrane Database Syst Rev. 2002;1:Cd000998.

35. Sin DD, Wu L, Man SF. The relationship between reduced lung function and cardiovascular mortality: a population-based study and a systematic review of the literature. Chest. 2005;127(6):1952-1959.

36. McGarvey LP, John M, Anderson JA, Zvarich M, Wise RA. Ascertainment of cause-specific mortality in COPD: operations of the TORCH Clinical Endpoint Committee. Thorax. 2007;62(5):411-415.

37. Nici L, ZuWallack R. An official American Thoracic Society workshop report: the integrated care of the COPD patient. Proc Am Thorac Soc. 2012;9(1):9-18

38. Campo G, Pavasini R, Malagù M, et al. Chronic obstructive pulmonary disease and ischemic heart disease comorbidity: overview of mechanisms and clinical management. Cardiovasc Drugs Ther. 2015; 29(2):147-157.

39. Calverley PM, Anderson JA, Celli B, et al; TORCH investigators. Salmeterol and fluticasone propionate and survival in chronic obstructive pulmonary disease. $N$ Engl J Med. 2007;356(8):775-789.

40. Lehouck A, Boonen S, Decramer M, Janssens W. COPD, bone metabolism, and osteoporosis. Chest. 2011;139(3):648-657.

41. Graat-Verboom L, Wouters EF, Smeenk FW, van den Borne BE, Lunde R, Spruit MA. Current status of research on osteoporosis in COPD: a systematic review. Eur Respir J. 2009;34(1):209-218.

42. Kunik ME, Roundy K, Veazey C, et al. Surprisingly high prevalence of anxiety and depression in chronic breathing disorders. Chest. 2005; 127(4):1205-1211.

43. Coultas DB, Edwards DW, Barnett B, Wludyka P. Predictors of depressive symptoms in patients with COPD and health impact. COPD. 2007;4(1):23-28.

44. Kunik ME, Veazey C, Cully JA, et al. COPD education and cognitive behavioral therapy group treatment for clinically significant symptoms of depression and anxiety in COPD patients: a randomized controlled trial. Psychol Med. 2008;38(3):385-396.

45. Eiser N, Harte R, Spiros K, Phillips C, Isaac MT. Effect of treating depression on quality-of-life and exercise tolerance in severe COPD. COPD. 2005;2(2):233-241.

46. Maurer J, Rebbapragada V, Borson S, et al; ACCP Workshop Panel on Anxiety and Depression in COPD. Anxiety and depression in COPD: current understanding, unanswered questions, and research needs. Chest. 2008;134(4 suppl):43s-56s.

47. Argyropoulou P, Patakas D, Koukou A, Vasiliadis P, Georgopoulos D. Buspirone effect on breathlessness and exercise performance in patients with chronic obstructive pulmonary disease. Respiration. 1993;60(4):216-220.

48. Bhullar S, Phillips B. Sleep in COPD patients. COPD. 2005;2(3): $355-361$.

49. Marin JM, Soriano JB, Carrizo SJ, Boldova A, Celli BR. Outcomes in patients with chronic obstructive pulmonary disease and obstructive sleep apnea: the overlap syndrome. Am J Respir Crit Care Med. 2010;182(3): $325-331$.

50. Machado MC, Vollmer WM, Togeiro SM, et al. CPAP and survival in moderate-to-severe obstructive sleep apnoea syndrome and hypoxaemic COPD. Eur Respir J. 2010;35(1):132-137.

51. Cochrane MG, Bala MV, Downs KE, Mauskopf J, Ben-Joseph RH. and inhalation technique. Chest. 2000;117(2):542-550. Inhaled corticosteroids for asthma therapy: patient compliance, devices,

52. van Boven JF, Tommelein E, Boussery $\mathrm{K}$, et al. Improving inhaler adherence in patients with chronic obstructive pulmonary disease: a cost-effectiveness analysis. Respir Res. 2014;15:66.

53. Bjermer L. The importance of continuity in inhaler device choice for asthma and chronic obstructive pulmonary disease. Respiration. 2014; 88(4):346-352.

54. Broeders ME, Sanchis J, Levy ML, Crompton GK, Dekhuijzen PN. The ADMIT series - issues in inhalation therapy. 2. Improving technique and clinical effectiveness. Prim Care Respir J. 2009;18(2):76-82.

55. Dolovich MB, Ahrens RC, Hess DR, et al; American College of Chest Physicians, American College of Asthma, Allergy, and Immunology. Device selection and outcomes of aerosol therapy: evidence-based guidelines: American College of Chest Physicians/American College of Asthma, Allergy, and Immunology. Chest. 2005;127(1):335-371.

56. Simoni-Wastila L, Wei YJ, Qian J, et al. Association of chronic obstructive pulmonary disease maintenance medication adherence with all-cause hospitalization and spending in a medicare population. $\mathrm{Am} J$ Geriatr Pharmacother. 2012;10(3):201-210.

57. Vestbo J, Anderson JA, Calverley PM, et al. Adherence to inhaled therapy, mortality and hospital admission in COPD. Thorax. 2009;64(11): 939-943.

58. Khdour MR, Hawwa AF, Kidney JC, Smyth BM, McElnay JC. Potential risk factors for medication non-adherence in patients with chronic obstructive pulmonary disease (COPD). Eur J Clin Pharmacol. 2012; 68(10): 1365-1373

59. Bourbeau J, Julien M, Maltais F, et al; Chronic Obstructive Pulmonary Disease axis of the Respiratory Network Fonds de la Recherche en Santé du Québec. Reduction of hospital utilization in patients with chronic obstructive pulmonary disease: a disease-specific self-management intervention. Arch Intern Med. 2003;163(5):585-591.

60. Adams SG, Smith PK, Allan PF, Anzueto A, Pugh JA, Cornell JE. Systematic review of the chronic care model in chronic obstructive pulmonary disease prevention and management. Arch Intern Med. 2007; 167(6):551-561.

61. Jain VV, Allison R, Beck SJ, et al. Impact of an integrated disease management program in reducing exacerbations in patients with severe asthma and COPD. Respir Med. 2014;108(12):1794-1800.

62. Fan VS, Gaziano JM, Lew R, et al. A comprehensive care management program to prevent chronic obstructive pulmonary disease hospitalizations: a randomized, controlled trial. Ann Intern Med. 2012; 156(10):673-683.

63. Christie JD, Edwards LB, Kucheryavaya AY, et al. The registry of the International Society for Heart and Lung Transplantation: twentyseventh official adult lung and heart-lung transplant report -2010 . J Heart Lung Transplant. 2010;29(10):1104-1118.

64. Lahzami S, Bridevaux PO, Soccal PM, et al. Survival impact of lung transplantation for COPD. Eur Respir J. 2010;36(1):74-80.

65. Yusen RD, Edwards LB, Kucheryavaya AY, et al; International Society for Heart and Lung Transplantation. The registry of the International Society for Heart and Lung Transplantation: thirty-first adult lung and heart-lung transplant report - 2014; focus theme: retransplantation. J Heart Lung Transplant. 2014;33(10):1009-1024.

66. Recipients. SRoT. OPTN/SRTR 2012 Annual Data Report: Lung. 2012. Available from: http://srtr.transplant.hrsa.gov/annual_reports/2012/

\section{Dovepress}

\section{Publish your work in this journal}

The International Journal of COPD is an international, peer-reviewed journal of therapeutics and pharmacology focusing on concise rapid reporting of clinical studies and reviews in COPD. Special focus is given to the pathophysiological processes underlying the disease, intervention programs, patient focused education, and self management protocols.

This journal is indexed on PubMed Central, MedLine and CAS. The manuscript management system is completely online and includes a very quick and fair peer-review system, which is all easy to use. Visit $\mathrm{http}: / / \mathrm{www}$.dovepress.com/testimonials.php to read real quotes from published authors. 